\title{
Bilateral Multicentric Metachronous Benign Phylloides Tumor: A Rare Presentation
}

\author{
Authors \\ Varsha Pandey $^{1}$, V. Sudarshan ${ }^{2}$, Naveen K. Verma ${ }^{3}$, Karan S. Chandrakar ${ }^{4}$ \\ Rajni P. Verma ${ }^{5}$ \\ ${ }^{1}$ Assistant Professor, Department of Pathology, C.C. M. Medical College Durg (Chhattisgarh) \\ ${ }^{2}$ Professor \& Head Department of Pathology, C.C. M. Medical College Durg (Chhattisgarh) \\ ${ }^{3}$ Assistant Professor, Department of Pathology, C.C. M. Medical College Durg (Chhattisgarh) \\ ${ }^{4}$ Assistant Professor, Department of Pathology, C.C. M. Medical College Durg (Chhattisgarh) \\ ${ }^{5}$ Demonstrator, Department of Pathology, C.C. M. Medical College Durg (Chhattisgarh)
}

Email-varshanema@live.com

\begin{abstract}
Phylloides tumor is rare stromal tumor of breast. It is common in median age group. It is known for its presentation as unilateral huge mass. However, the diagnosis of phylloides tumor can be neither made or nor ruled out by the size alone. Bilateral phylloides tumors are distinctly uncommon. Most of them are malignant and metachronous. We present a rare case of bilateral multicentric benign metachronous phylloides tumor of breast in a young female of 20 years of age.

Key words: Benign, bilateral, metachronous, multicentric, phylloides tumor
\end{abstract}

\section{Introduction}

Phylloides tumors of breast are rare stromal tumor with a very low rate of bilateral occurrence. It is biphasic tumor of breast. Its etiology and pathogenesis are exactly not clear ${ }^{[1]}$. It constitutes 0.3 to $1 \%$ of all breast neoplasm ${ }^{[2]}$. The average age of presentation is 45 years $^{[3]}$. It usually presents as solitary, round, relatively well circumscribed, firm, rubbery and unilateral mass. The overlying skin is usually unremarkable. The nipple may be flattened. The cut surface is solid, grey white \& shows cleft like spaces due to presence of an exaggerated Intracanalicular pattern of growth. Areas of necrosis, cystic degeneration and hemorrhage may present which indicate malignancy. Many phylloides tumors are large and some reach huge dimensions but other measure less than $5 \mathrm{~cm}$. Microscopically the two key features of phylloides tumor are stromal hypercellularity \& presence of benign glandular elements ${ }^{[4]}$.

\section{Case Report}

A 20 years female, presented with multiple masses in both the breast for three months duration. The physical examination showed solitary, firm mass on right side measuring $3 \times 2.5 \times 2$ and on left side four nodular masses of varying sizes were present. As per the patient the masses were metachronous, the left sided breast lumps were felt earlier followed by right sided mass. Other clinical and investigation findings 
were unremarkable. Ultrasonography showed heterogenous hypoechoic masses on both the sides.

The masses from both the sides were excised \& sent for histopathological examination. The postoperative follow up was uneventful. The patient did not show any evidence of recurrence and metastasis till date.

\section{Gross Features}

We received lumpectomy specimen from both the sides separately.

The lump from right side was solitary, lobulated, well demarcated, grey to yellow measuring $4.5 \times 3 \times 2 \mathrm{~cm}$. Cut surface was glistening white (Figure 1). From the left side there were four nodular, irregular, grey to yellow masses of varying sizes, largest one measuring $5 \times 4 \times 2 \mathrm{~cm}$. Cut surface of these masses showed cleft like spaces (Figure 2).

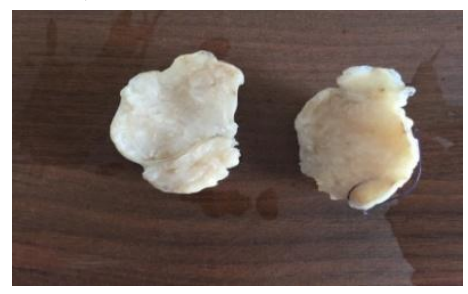

Figure 1- Single grey white mass from right side. Cut surface is glistening white.

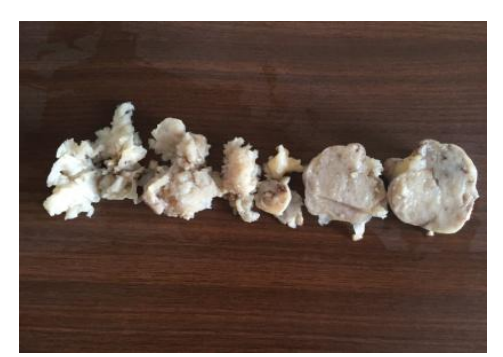

Figure 2- Multiple grey white masses from left side. Cut surface showing cleft like spaces.

\section{Microscopy}

Multiple haematoxylin \& eosin stained sections from both sided lumps showed features of biphasic neoplasm with predominance of stromal component. The tumor was composed of highly cellular connective tissue having interlacing bundles of fibroblast like cells lacking atypia \& mitotic activity. There were clefts lined by the double layered plump cuboidal epithelial cells (Figure 3).

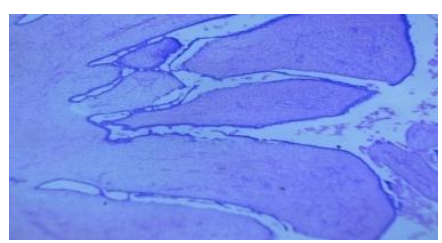

Figure 3- Photomicrograph showing biphasic tumor with stromal hyperplasia (Left sided mass).

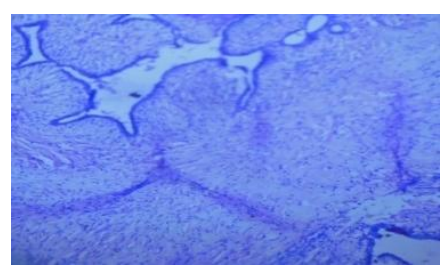

Figure 4- Photomicrograph showing stromal hyperplasia without atypia (Right sided mass).

\section{Discussion}

Phylloides tumor was previously called as cystosarcoma phylloides based on leaf-like gross appearance ${ }^{[5]}$. Only around 3\% cases are bilateral. Bilateral tumors are mostly malignant and are metachronous ${ }^{[6,7,8,9]}$. Marti and Hiotis present the first reported case of multiple, bilateral phylloides tumor of the breasts in an adolescent girl ${ }^{[10]}$. Phylloides tumor clinically, macroscopically \& microscopically resembles fibroadenoma but former occur in an older age group than fibroadenoma. Phylloides tumor is usually larger than fibroadenoma. Phylloides tumors have surface projections, incomplete removal of which result in local recurrence which is much more common in phylloides tumor than fibroadenoma ${ }^{[11,12,13]}$. The most important distinguishing feature is stromal hypercellularity. But in tumors with low stromal cellularity the features like stromal nuclear pleomorphism, mitotic rate, architecture and stromal overgrowth indicate diagnosis of phylloides tumor rather than fibroadenoma ${ }^{[13]}$.

Grading of phylloides tumor is based on semiquantitative assessment of stromal cellularity, cellular pleomorphism, mitotic activity, margin appearance, and stromal distribution. Tumors with modest stromal hypercellularity, little cellular 
pleomorphism, 0-4 mitoses per 10 high power field, well circumscribed, pushing margins, and minimal or moderate stromal overdevelopment are classified as Benign. Borderline tumors are defined as tumors representing modest stromal hypercellularity, moderate cellular pleomorphism, 5-9 mitoses per 10 high power field, intermediately infiltrated margins, and moderate stromal overgrowth. Malignant tumors show marked stromal hypercellularity and cellular pleomorphism, more than 10 mitoses per 10 high power field and marked stromal overgrowth ${ }^{[14]}$.

The possibility of local recurrence and metastasis is $6-10 \%$ in benign phylloides tumors, $25-32 \%$ in borderline phylloides tumors, and over $25 \%$ in malignant phylloides tumors ${ }^{[15,16]}$. Stromal overgrowth, stromal atypia, mitotic activity, surgical margin of tumor, heterologous stromal component and histologic grade are significantly correlated with metastasis. Lungs and the bone are the most common sites for metastasis ${ }^{[17-21]}$.

\section{Conclusion}

Phylloides tumor rarely present as bilateral multicentric masses. This case is one of the rare cases of bilateral multicentric benign phylloides tumors.

\section{References}

1. Tse GM, Niu Y, Shi HJ. Phyllodes tumor of the breast. an update. Breast Cancer. May 12. [Epub ahead of print], 2009. (PMID: 19434472).

2. Keelan PA, Myers JL, Wold, et al. Phylloides tumor: Clinicopathologic review of 60 patients and flow cytometric analysis in 30 patients. Hum Pathol. 1992;23:1048-54.

3. Bernstein L, Deapen D, Ross RK. The descriptive epidemiology of malignant cystosarcoma phylloidestumors of breast. Cancer 1993, 71:3020- 3024.

4. Azzopardi JG. Problems in breast pathology. In Benington JL, Major problems in pathology. Philadephia 1979, W.B. Saunders.

5. Fiks A. Cystosarcoma phylloides of the mammary gland. Muller's tumor. For the $180^{\text {th }}$ birthday of Johannes Muller. Virchow's Arch [A] 1981, 392: 1-6.

6. Beb HSSOUNA j, Damak T, Gamoudi A etal. Phyllodes tumors of the breast A case series of 106 patients. Am J surg. 2006;192:141-7.

7. Finocchi L, Covarelli P, Rulli A, Servoli A, Noya G. Bilateral phylloid cystosarcoma of the breast: a case report and review of the literature. Chir Ital. 2008; 60(6): 867-872. (PMID: 19256279).

8. Mrad K, Driss M, Maalej M, Romdhane KB. Bilateral cystosarcoma phyllodes of the breast: a case report of malignant form with contralateral benign form. Ann Diagn Pathol. 2000; 4(6):370-3722. (PMID: 11149968).

9. Ezeome ER, Okafor OC, Nwajiobi CE, Osuagwu CC. Bilateral benign phyllodes tumor in a nulliparous woman: a case report and review of literature. Niger $\mathbf{J}$ Clin Pract. 2007; 10(1):66-69.( PMID: 17668718).

10. Marti J.L., K. Hiotis K. Excision of 13 phyllodes bilateral breast tumors in one patient. J Clin Oncol 26: 2008 (May 20 suppl; abstr 11584)

11. Konstantakos AK, Graham DJ. Cystosarcoma phyllodes tumors in men. Am Surg. 2003; 69(9): 808-811,. (PMID: 14509333)

12. Hawkins RE, Schofield JB, Fisher C, Wiltshaw E, McKinna JA. The clinical and histologic criteria that predical metastases from cystosarcoma phyllodes. Cancer. 1992; 69(1):141-147. (PMID: 1309302).

13. Moffat CJC, Pinder SE, Dixon AR, et al. Phylloides tumors of breast : a clinicopathologic review of 32 cases. Histopathology 1995; 27:205-218. 
14. Bellocq J, Magro G. Fibroepithelial tumors. In: Tavassoli F, Devilee P, editors. World Health Organization classification o $\mathrm{f}$ tumors. Pathology and genetics of tumors of the breast and female genital organs. Lyon: IARC Press; 2003; 99-103.

15. Zurrida S, Bartoli C, Galimberti V, Squicciarini P, Delledonne V, Veronesi P, Bono A, de Palo G, Salvadori B. Which theraphy for unexpected phylloides tumor of the breast. Eur J Cancer. 1992; 28: 654657. (PMID: 1317204)

16. Rajan PB, Cronar ML, Rosen PP: Cystosarcoma phyllodes in adolescent girls and young women: a study of 45 patients. Am J Surg Pathol. 1988; 22(1): 64-69. (PMID: 9422317)

17. Chaney AW, Pollack A, McNeese MD, Zagars GK, Pisters PW, Pollock RE, Hunt KK. Primary treatment of cystosarcoma pyllodes of the breast. Cancer. 2000; 89: 1502-1511. (PMID: 11013364).

18. Ben Hassouna J, Damak T, Gamoudi A, Chargui R, Khomsi F, Mahjoub S, Slimene M, Ben Dhiab T, Hechiche M, Boussen H, Rahal K. Phyllodes tumors of the breast: a case series of 106 patients. Am J Surg. 2006; 192: 141-147. (PMID: 16860620).

19. Macdonald OK, Lee CM, Tward JD, Chappel CD, Gaffney DK. Malignant phyllodes tumor of the female breast. Cance r. 2006; 107: 2127-2133. (PMID: 16998937).

20. C heng SP, Chang YC, Liu TP, Lee JJ, Tzen CY, Liu CL. Phyllodes tumor of the breast: the challenge persists. Word J Surg 2006; 30: 1414-1421. (PMID: 16865317).

21. Karim RZ, Gerega SK, Yang YH, Spillane A, Carmalt H, Scolyer RA, Lee CS. Phyllodes tumors of the breast: a clinicopathological analysis of 65 cases from a single institution. Breast. 2009; 18(3):165-70. (PMID:19329316). 